\title{
Infection with Hepatitis B Virus May Increase the Serum Concentrations of Osteopontin
}

\author{
Hua-Bing Liu ${ }^{a, b}$ Qin-Yan Chen ${ }^{a} \quad$ Xue-Yan Wang ${ }^{a} \quad$ Lu-Juan Zhang ${ }^{a}$ \\ Li-Ping $\mathrm{Hu}^{\mathrm{a}}$ Tim J. Harrison ${ }^{\mathrm{c}}$ Chao Wang ${ }^{\text {a }}$ Zhong-Liao Fang ${ }^{\mathrm{a}}$ \\ aGuangxi Zhuang Autonomous Region Center for Disease Prevention and Control, Guangxi Key Laboratory for

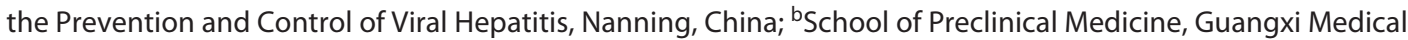 \\ University, Nanning, China; 'Division of Medicine, UCL Medical School, London, UK
}

\section{Keywords}

Hepatitis B virus · HBsAg · Osteopontin · Hepatocellular carcinoma

\begin{abstract}
Background: Serum osteopontin (OPN) concentrations were found to be significantly increased in patients infected with hepatitis B virus (HBV) and patients with hepatocellular carcinoma (HCC). Objective: The aim of this study was to determine the association among HCC, OPN, and HBV. Methods: Two hundred and forty-one subjects were recruited and divided into 6 groups: healthy controls, asymptomatic HBsAg carriers, $\mathrm{HBsAg}(-)$ patients with other tumors, $\mathrm{HBsAg}(+)$ chronic liver disease patients, $\mathrm{HBsAg}(+)$ patients with $\mathrm{HCC}$, and $\mathrm{HBsAg}(-)$ patients with HCC or liver cirrhosis (LC). Serum concentrations of OPN and HBsAg were measured and analyzed. Results: OPN concentrations in the HBsAg (+) HCC group were significantly higher than the healthy control group and the HBsAg (-) patients with other cancers (both $p=0.0001)$. The OPN concentrations of the HBsAg (-) patients with HCC or LC also did not differ significantly from those of the healthy control group ( $p=0.075)$. There is a correlation between the titer of $\mathrm{HBsAg}$ and concentrations of OPN in all $3 \mathrm{HBsAg}(+)$ groups (all $p$ values $<0.05$ ). Conclusions: Infection with HBV may increase the serum concentra-
\end{abstract}

tions of OPN. The association of OPN and HCC may be not attributable to tumor development per se but, rather, to HBV infection.

(C) 2021 The Author(s)

Published by S. Karger AG, Basel

\section{Introduction}

Liver cancer is one of the most common cancers worldwide, being the fifth most common cancer in men worldwide and the seventh in women. Hepatocellular carcino$\mathrm{ma}$ (HCC) is the most common form of liver cancer, but there is a wide geographic variability in HCC incidence. More than $80 \%$ of cases occur in either sub-Saharan Africa or in Eastern Asia, with 1 country alone, China, accounting for over $50 \%$ of cases $[1,2]$. Guangxi ranks fourth among 27 provinces in China in terms of HCC mortality [3]. Persistent hepatitis B virus (HBV) infection can cause acute and chronic liver diseases and is strongly associated with the development of cirrhosis and HCC [4].

The secreted phosphoprotein, osteopontin (OPN), was first described in 1979 as a protein associated with the transformation of epithelial cells [5]. This 300-amino acid protein is encoded by the human gene SPP1 [6] and its murine counterpart Spp1 [7] and is rich in aspartic acid 
residues. It has acidic characteristics and O-linked and $\mathrm{N}$-linked oligosaccharides [8]. The biological functions of OPN are diverse, and it plays important roles in inflammation, cellular viability, and cancer, as well as cardiovascular diseases, diabetes, biomineralization, and renal stone disease, through various mechanisms [9].

The involvement of OPN in the liver was first reported in rats after carbon tetrachloride intoxication. OPN was found in Kupffer cells, hepatic macrophages, and hepatic stellate cells in the necrotic areas and was shown to contribute to the infiltration of macrophages into these areas [10]. Further studies revealed that OPN exacerbates the progression of liver diseases under various pathological conditions by interacting with av integrin, CD44, vimentin, and MyD88 [11]. OPN may be an independent risk factor associated with acute-on-chronic liver failure due to HBV [12]. Serum OPN concentrations have been reported to be significantly higher in HCC patients than a comparison group [13], although other studies found that plasma OPN concentrations did not differ significantly between cirrhotic patients with and without HCC $[14,15]$.

Several studies concluded that the serum concentrations of OPN may increase after infection with pathogens, including Leishmania amazonensis, schistosomes, virulent mycobacterium bovis BCG, and dengue virus [1619]. Infection with hepatitis $C$ virus (HCV) may also increase the serum concentration of OPN [20]. However, it is unclear whether infection with HBV increases the serum concentration of OPN. Here, we carried out a casecontrol study to determine the association of $\mathrm{HBV}$ infection with the concentrations of OPN. We also determined whether OPN might be useful as a biomarker to predict HCC in Guangxi, southern China.

\section{Materials and Methods}

\section{Study Subjects and Sample Design}

The study subjects comprised 6 groups: healthy controls (50 subjects), asymptomatic HBsAg carriers (62 subjects), HBsAg (-) patients with other tumors (39 subjects who suffered from lung cancer, kidney cancer, etc.), HBsAg (+) chronic liver disease patients (28 subjects), HCC patients with HBsAg (+) (50 subjects), and HBsAg $(-)$ patients with HCC or liver cirrhosis (LC) (12 subjects). The healthy control and asymptomatic HBsAg carrier groups were recruited from LongAn county, Guangxi. The latter were recruited from our LongAn cohort, with sequence information available regarding HBV basal core promoter (BCP) mutations [21]. The HBsAg (-) patients with other tumors and HBsAg (+) chronic liver disease patients, including chronic hepatitis B (CHB) and LC, were recruited from the First Affiliated Hospital of Guangxi Medical University. The HCC patients with
HBsAg (+) and HBsAg (-) patients with HCC or LC were recruited from First Affiliated Hospital of Guangxi Medical University and LongAn county hospital. None of the study subjects with the HBsAg (+) received antiviral therapy before sampling. Each study subject provided a 5-mL sample of blood by venepuncture for the subsequent analysis.

The diagnosis of HCC was made, as described previously [21], by 1 or more of the following: (a) surgical biopsy; (b) elevated serum alpha-fetoprotein (AFP) (levels $\geq 400 \mathrm{ng} / \mathrm{mL}$ ), excluding pregnancy, genital cancer, and other liver diseases, including metastasis of tumors from other organs, plus clinical symptoms or 1 image (ultrasound [US] or computed tomography [CT]); (c) elevated serum AFP (levels $<400 \mathrm{ng} / \mathrm{mL}$ ), excluding pregnancy, genital cancer, and other liver diseases including metastasis of tumors from other organs, plus 2 images (US and CT) or 1 image (US or CT) and 2 positive HCC markers such as DCP, GGT II, AFU, and CA19-9.

LC was diagnosed clinically according to the features of esophageal varices, ascites, and hepatic encephalopathy. The diagnosis was confirmed by abdominal imaging (coarse parenchyma with enlargement or shrinkage of the liver; splenomegaly; ascites found by US, CT, or magnetic resonance imaging) or surgical findings (laparoscopy and autopsy), combined with indicative laboratory test results (low platelet count and albumin, the high level of serum bilirubin, and/or prolonged prothrombin time) [22].

The diagnostic criteria for $\mathrm{CHB}$ include a history of hepatitis $\mathrm{B}$ or positivity for HBsAg for at least 6 months and the continuing presence of HBsAg and/or HBV DNA in the serum. The diagnosis of HBV infection is based on serologic markers, virological markers, liver function tests, and biochemical assays, as well as other clinical and supportive findings. Exclusion criteria were coinfection with hepatitis $\mathrm{C}$ virus, hepatitis $\mathrm{D}$ virus, or human immunodeficiency virus [22]. Asymptomatic HBsAg carriers are defined as those who were positive for HBsAg for at least 6 months and clinical symptoms and with normal liver function.

\section{Serological Testing}

Sera were tested for the markers of HBV infection and the concentrations of serum AFP, using enzyme immunoassays (Beijing Wantai Biopham Company Limited, Beijing, China). Alanine aminotransferase (ALT) levels were determined using a Reitman kit (DiaSys Diagnostic Systems [Shanghai], Shanghai, China).

\section{Measurement of Serum OPN Concentrations}

OPN concentrations were measured using an ELISA kit (HePeng Biological Company Limited, Shanghai, China) according to the manufacturer's protocol. The kit standards were used for construction of standard curves. The sensitivity of this assay is $1.0 \mathrm{ng} /$ $\mathrm{mL}$.

\section{Measurement of Serum HBsAg Titers}

Serum HBsAg titers were measured using a commercial chemiluminescent microparticle immunoassay on the ARCHITECT i2000SR platform, with Abbott Architect HBsAg reagents (Abbott Ireland Diagnostics Division, Finisklin Business Park, Sligo, Ireland) and with a dynamic range of $0.05-250 \mathrm{IU} / \mathrm{mL}$. In cases where the HBsAg titers were $>250 \mathrm{IU} / \mathrm{mL}$, serial 1:500 dilutions were performed according to the manufacturer's instructions to bring them into the range of the calibration curve. The lower limit of detection of this assay is $0.05 \mathrm{IU} / \mathrm{mL}$. 
Measurement of Serum Viral Loads

Serum HBV DNA concentrations were quantified by real-time PCR using commercial reagents (Sansure Biotech Inc [Hunan, China]) in an ABI Prism 7500 sequence detection system (Applied Biosystems, Foster City, CA, California, USA), with a dynamic range of $1 \times 10^{2}-5 \times 10^{9} \mathrm{IU} / \mathrm{mL}$.

\section{Statistical Analysis}

The data are presented as median (range). The medians were compared between groups using the Mann-Whitney test. Simple and multiple linear regression analyses were performed to identify independent factors correlated with serum OPN concentrations. A logarithmic transformation was applied to all viral load and HBsAg measurements, prior to the regression analysis, to achieve an approximately normal distribution. All $p$ values were 2 -tailed and $p<0.05$ was considered to be significant. All statistical analyses were performed using the SPSS software (ver.16.0; Chicago, IL, USA).

\section{Results}

\section{General Information}

There are 241 study subjects, 166 males and 75 females. The average age was $47.3 \pm 10.5$ years old. The mean concentration of serum OPN was $2,368.5 \mathrm{ng} / \mathrm{mL}$ (range: 16.2-9,341.7). The study subjects were divided into 6 groups: healthy controls, HBsAg (-) patients with other cancers, HBsAg (-) patients with HCC or LC, asymptomatic HBsAg carriers, $\mathrm{HBsAg}(+)$ chronic liver disease patients, and HBsAg (+) HCC patients (Table 1; Fig. 1).

The Association of the Serum Concentrations of OPN with the Development of HCC

When the median concentrations of serum OPN among all HCC patients were compared with those of the healthy control group using the Mann-Whitney test, HBsAg (-) patients with other cancers, asymptomatic HBsAg carriers, and HBsAg (+) chronic liver disease patients, the $p$ values were $0.0001,0.0001,0.049$, and 0.454 , respectively. The median concentration of serum OPN in the LC group (17 subjects) was also compared with that of the healthy control group and the $p$ value is 0.0001 . These results suggest that the concentrations of serum OPN are associated with the development of LC and HCC.

We carried out a stratified analysis of the presence of HBsAg in patients with LC or HCC. After grouping together, the HBsAg (-) patients with HCC and with chronic liver disease to form an independent group, named the HBsAg (-) patients with HCC or LC group (Table 1), we compared the concentrations of serum OPN in the

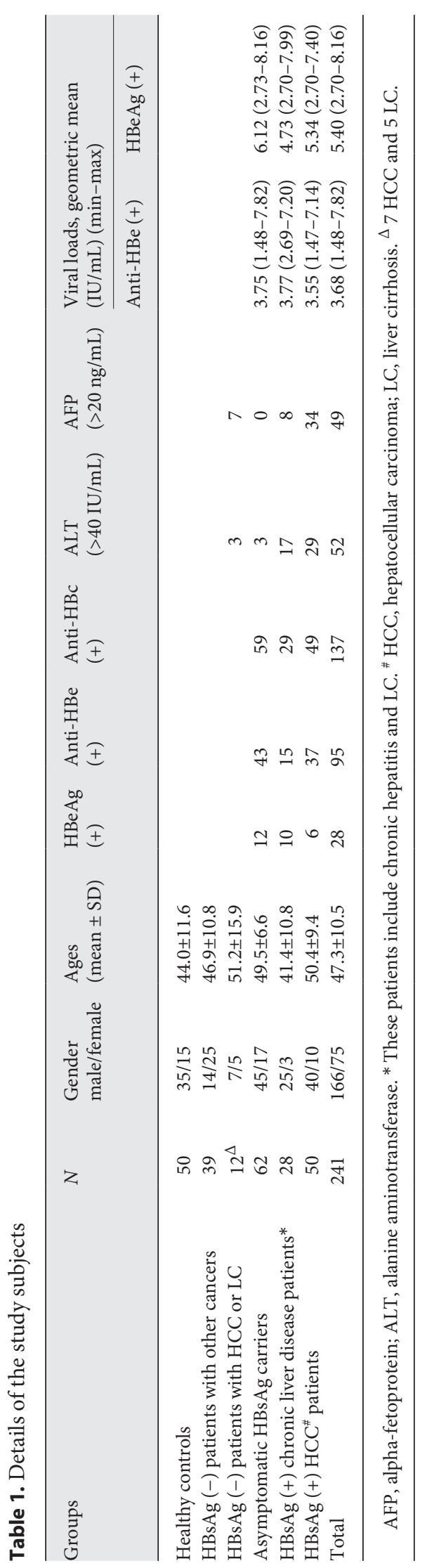

Liu/Chen/Wang/Zhang/Hu/Harrison/ Wang/Fang 


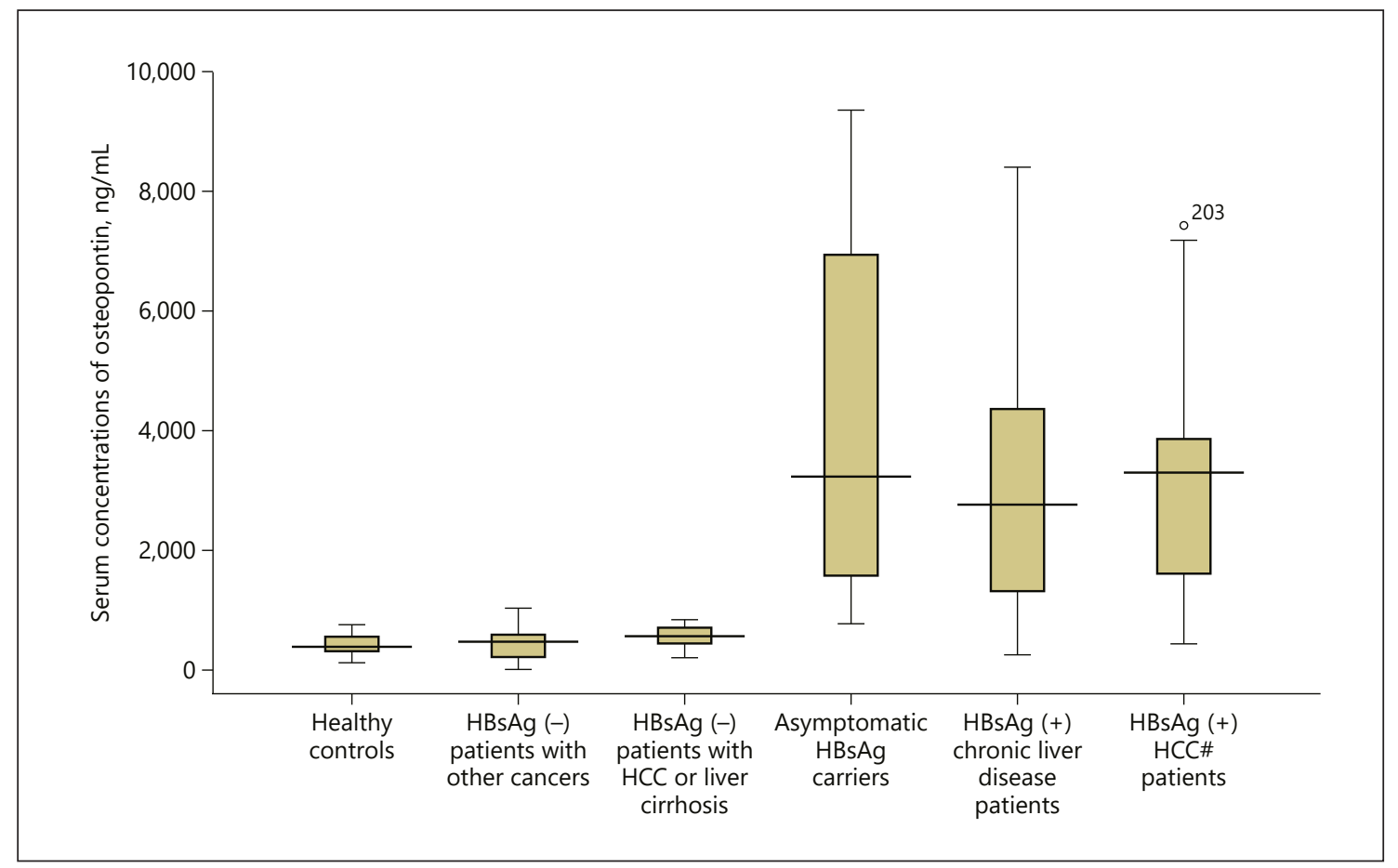

Fig. 1. Comparative analysis of the serum concentrations of OPN. The box plot shows median values, upper and lower quartiles, and the largest and smallest observations. Concentrations of OPN of the healthy control group $(n=50)(\mathbf{a})$; Concentrations of OPN of the other tumors group $(n=39)(\mathbf{b})$; Concentrations of OPN of the HBsAg $(-)$ patients with HCC or LC group $(n=12)(\mathbf{c})$; Concentrations of OPN of the asymptomatic HBsAg carrier group $(n=62)(\mathbf{d})$; Concentrations of the OPN of the chronic liver diseases group $(n=28)(\mathbf{e})$; Concentrations of the OPN of the HCC group $(n=50)(\mathbf{f})$. OPN, osteopontin; HCC, hepatocellular carcinoma; LC, liver cirrhosis.

HBsAg (+) HCC patient group with the 4 groups above; the $p$ values are $0.0001,0.0001,0.360$, and 0.588 , respectively. The median concentration of serum OPN in the HBsAg (+) LC group (13 subjects) was also compared with that of the healthy control group. The $p$ value is 0.0001 and, clearly, the analysis yielded similar results to those above.

However, the median concentration of serum OPN of the HBsAg (-) patients with HCC or LC was compared with that of the healthy control group. It is notable that the difference is not significant $(p=0.075)$, suggesting that the association between OPN and HCC may not be attributable to HCC per se but, rather, to infection by HBV.

\section{The Association of Viral Factors with the Serum Concentrations of OPN}

In order to determine which viral factors are associated with the serum concentrations of OPN, we determined the association between viral loads and OPN for the asymptomatic HBsAg carrier group, HBsAg (+) chronic liver disease patients' group, HBsAg (+) HCC patients' group and all of the 3 groups together, using simple linear regression analysis. The $p$ values are $0.439,0.631$, and 0.217 , respectively (Fig. $2 \mathrm{a}-\mathrm{c}$ ), suggesting that viral loads are not associated with serum concentrations of OPN.

The serum concentrations of OPN also were compared between asymptomatic HBsAg carriers with BCP wild type $(N=38)$ and double mutations $(1762 \mathrm{~T}, 1764 \mathrm{~A})$ $(N=24)$, in the HBV genome, using the Mann-Whitney test. The difference is not significant $(Z=-0.123, p=$ $0.902)$, suggesting that the double mutations are not associated with serum concentrations of OPN.

We determined the association of the serum titer of HBsAg and serum concentrations of OPN for the asymptomatic HBsAg carrier group using simple linear regression analysis. We found that there is a correlation between the serum titer of HBsAg and serum concentrations of OPN ( $p=0.028)$, suggesting that the serum titer 


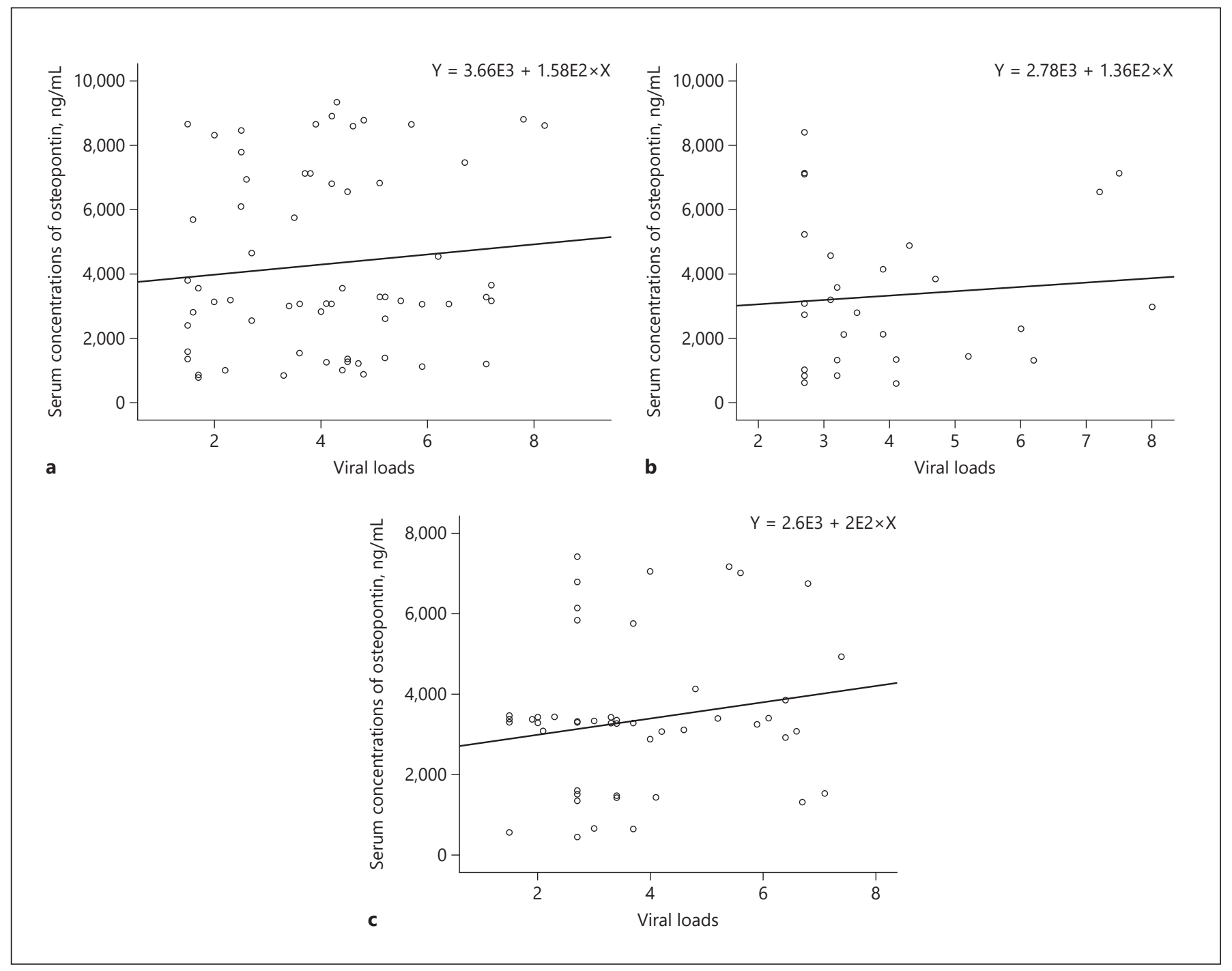

Fig. 2. a Simple linear regression analysis of serum viral loads and OPN for asymptomatic HBsAg carriers. $p=$ 0.439. b Simple linear regression analysis of serum viral loads and OPN for HBsAg (+) chronic liver disease patients. $p=0.631$. c Simple linear regression analysis of serum viral loads and OPN for HBsAg (+) HCC patients. $p=0.217$. OPN, osteopontin; HCC, hepatocellular carcinoma.

of HBsAg can predict the serum concentrations of OPN. We also analyzed the HBsAg $(+)$ chronic liver disease patients' group and HBsAg (+) HCC patients' group. We found that the $p$ values are 0.005 and 0.001 , respectively (Fig. 3a-c). Clearly, the results from each group indicate that the serum titer of HBsAg can predict the serum concentrations of OPN.

\section{Factors Associated with the Serum Concentrations of OPN}

Multivariate linear regression analysis was carried out to identify factors associated with the serum concentra- tions of OPN. The independent variables included sex, age, hepatitis B viral loads, HBsAg, HBeAg, ALT, and AFP. The results indicate that the serum titer of HBsAg is the only variable independently associated with the serum concentration of OPN (Table 2).

\section{Discussion}

To our knowledge, this is the first study to show that infection with HBV may increase the serum concentrations of OPN. Serum titers of HBsAg are independently 


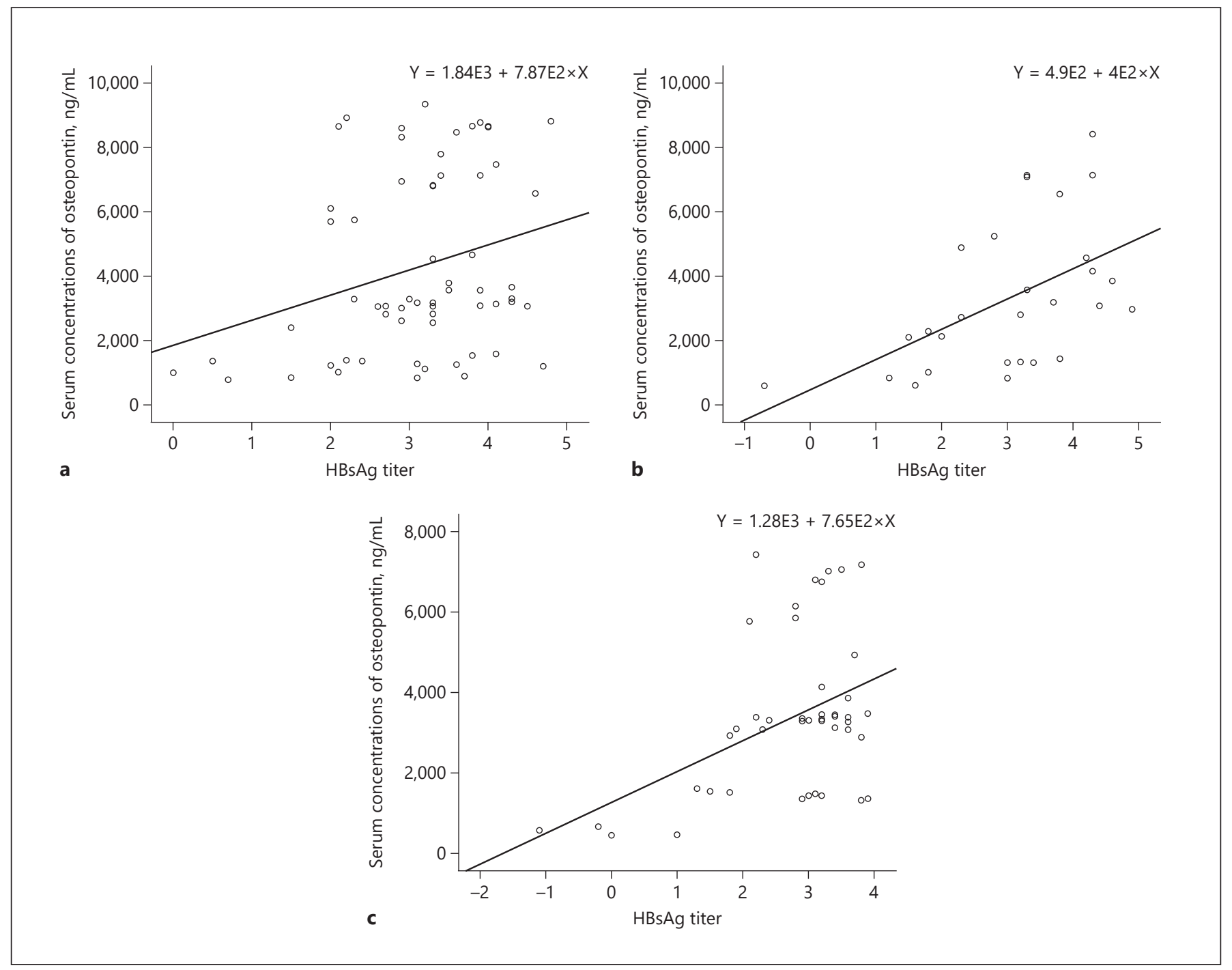

Fig. 3. a Simple linear regression analysis of serum titer of HBsAg and concentrations of OPN for asymptomatic HBsAg carriers. $p=0.028$. b Simple linear regression analysis of serum titer of HBsAg and concentrations of OPN for HBsAg $(+)$ chronic liver disease patients. $p=0.005$. c Simple linear regression analysis of serum titer of HBsAg and concentrations of OPN for HBsAg (+) HCC patients. $p=0.001$. OPN, osteopontin; HCC, hepatocellular carcinoma.

associated with the serum concentrations of OPN and can predict those concentrations. Sex, age, viral loads, viral gene mutations, $\mathrm{HBeAg}$, ALT, and AFP are not associated with serum OPN concentrations. Therefore, the association between OPN and HCC may not be attributable to HCC but to infection by HBV. OPN can be used as biomarker to predict HCC only in individuals with HBV infection. A strength of this study is the finding that the serum titer of HBsAg is an independent variable that predicts the serum concentration of OPN, and this was confirmed in all groups of samples. A weakness is that the sample sizes of HBsAg (+) patients with LC and HBsAg (-) patients with HCC or LC are not sufficient for stratification analysis, such as analysis according to HCC or $\mathrm{LC}$, to provide a strong conclusion.

Since the association of OPN with the liver was first reported in 1999 [5], an increasing number of studies have suggested that OPN is associated with liver diseases [11]. It has been reported that an elevated plasma OPN concentration is predictive of cirrhosis in patients with $\mathrm{HBV}$ infection [23]. It also has been reported that OPN may serve as a novel marker for early HCC [24]. A com- 
Table 2. Multivariate linear regression of factors associated with serum concentrations of OPN

\begin{tabular}{|c|c|c|c|c|c|c|c|}
\hline \multirow[t]{2}{*}{ Variables } & \multicolumn{2}{|c|}{ Unstandardized coefficients } & \multirow{2}{*}{$\begin{array}{l}\text { Standardized } \\
\text { coefficients } \\
\beta\end{array}$} & \multirow[t]{2}{*}{$t$} & \multirow[t]{2}{*}{ Sig } & \multicolumn{2}{|l|}{$95 \%$ CI for $B$} \\
\hline & $B$ & SE & & & & lower bond & upper bond \\
\hline Gender & 287.610 & 578.354 & 0.053 & 0.497 & 0.621 & -865.882 & $1,441.101$ \\
\hline Ages & -3.112 & 20.913 & -0.017 & -0.149 & 0.882 & -44.823 & 38.598 \\
\hline Viral loads & -51.526 & 140.294 & -0.041 & -0.367 & 0.715 & -331.334 & 228.282 \\
\hline HBsAg & 766.948 & 208.523 & 0.450 & 3.678 & 0.0001 & 351.063 & $1,182.834$ \\
\hline $\mathrm{HBeAg}$ & 843.667 & 581.184 & 0.169 & 1.452 & 0.151 & -315.468 & $2,002.801$ \\
\hline AFP & 0.000 & 0.009 & -0.005 & -0.043 & 0.966 & -0.019 & 0.018 \\
\hline ALT & 0.794 & 1.253 & 0.071 & 0.634 & 0.528 & -1.705 & 3.293 \\
\hline
\end{tabular}

OPN, osteopontin; AFP, alpha-fetoprotein; ALT, alanine aminotransferase.

bination of OPN and AFP was better than OPN or AFP alone for the diagnosis of HCC [25]. However, these conclusions were not supported by others $[14,15]$. Here, we show that OPN can be used as a biomarker to predict LC or HCC, or diagnose HCC or predict prognostic of HCC, only in individuals with HBV infection. However, our findings require confirmation because the numbers of HBsAg (+) patients with LC and HBsAg $(-)$ patients with HCC or LC are small.

OPN concentrations were found to be significantly increased in patients with CHB [26]. However, it is unclear, which viral factor is associated with serum concentration of OPN. Our study is the first to show that the serum titer of HBsAg can be used to predict serum concentrations of OPN.

Cell-mediated immunity is necessary for immune protection against most intracellular pathogens and OPN may play an important role in the development of cell-mediated immunity. OPN is expressed in T cells early in the course of bacterial infections (within $48 \mathrm{~h}$ ) and the interaction of the protein with macrophages can induce inflammatory responses $[27,28]$. L. amazonensis parasites also stimulate OPN gene expression [16]. Therefore, it may be postulated that $\mathrm{HBV}$ also stimulates OPN gene expression, resulting in the increase of serum concentrations of OPN.

OPN has an important protective role in enhancing the immune response in the face of various infections [28]. It has been reported that OPN could enhance the maturation and functioning of dendritic cells in the immune response to HBV antigens [29]. Therefore, our findings that serum titer of $\mathrm{HBsAg}$ are associated with serum concentrations of OPN may provide 1 more clue to elucidate the mechanisms of HBV oncogenesis. The association between OPN and cirrhosis and HCC is only apparent in patients infected with HBV.

OPN may increase the rate of virus replication and assembly $[19,30]$. Serum HBV DNA quantified by realtime fluorescent quantitative PCR is a key factor for determining the level of viral replication in the various phases of HBV infection [31]. But, in this study, viral load was not found to be associated with the concentrations of serum OPN, a finding is consistent with other studies [16].

The basal core promoter (BCP) double mutations (1762T, 1764A) in the HBV genome reduce the synthesis of $\mathrm{HBeAg}$ [32], which is associated with inflammation [33]. OPN plays an important role in inflammation [9]. However, in this study, neither BCP double mutations nor $\mathrm{HBeAg}$ correlated with the concentrations of serum OPN.

AFP is a glycoprotein, a member of the albuminoid gene family. It is produced in early pregnancy by the fetal liver and yolk sac [34] and undergoes an almost complete reduction of expression to become virtually undetectable in the serum a few weeks after birth. However, its expression may increase again in HCC [35]. AFP has been used as a serum marker for HCC in humans over the past several decades [36]. However, we found in this study that AFP was not associated with OPN.

It is unclear how HBV infection increases the concentrations of serum OPN. OPN may increase virus replication and assembly $[19,30]$, but why is the hepatitis B viral load not found to be associated with the concentrations of serum OPN? The HBV genotype may affect the OPN serum concentration but we did not investigate the effect of genotype in this study. Furthermore, our findings are 
from a specific region in Guangxi, China, and it is unclear, whether it can be replicated elsewhere. All of these questions need to be addressed.

\section{Acknowledgements}

We are indebted to the staff members of Centers for Disease Prevention and Control of Napo County, Guangxi, who assisted in recruiting the study subjects and handling the sera.

\section{Statement of Ethics}

Informed consent in writing was obtained from each individual. The study protocol conforms to the ethical guidelines of the 1975 Declaration of Helsinki and has been approved by the Guangxi Institutional Review Board (GXIRB 2018-0007).

\section{Conflict of Interest Statement}

The authors declare no conflicts of interest.

\section{Funding Sources}

This study was supported by the National Natural Science Foundation of China; Grant number: 30960326/C150501 and Guangxi Natural Science Foundation (Grant No. 20180191).

\section{Author Contributions}

Conceptualization: Fang Z.L., Harrison T.J., and Liu H.B. Data curation: Liu H.B., Chen Q.Y., Wang X.Y., Zhang L.J., Hu L.P., and Shi Y.L. Formal analysis: Wang X.Y. and Liu H.B. Investigation: Liu H.B., Chen Q.Y., Zhang L.J., Hu L.P., and Shi Y.L. Methodology: Liu H.B. and Wang X.Y. Supervision: Fang Z.L. Writing-original draft: Liu H.B. and Wang X.Y. Writing-review \& editing: Fang Z.L. and Harrison T.J.

\section{References}

1 McGlynn KA, London WT. Epidemiology and natural history of hepatocellular carcinoma. Best Pract Res Clin Gastroenterol. 2005 19(1):3-23.

2 El-Serag HB. Epidemiology of viral hepatitis and hepatocellular carcinoma. Gastroenterology. 2012;142(6):1264-e1.

3 Zhang S, Li L, Lu F. [Mortality of primary liver cancer in China from 1990 through 1992]. Zhonghua Zhong Liu Za Zhi. 1999;21(4): 245-9.

4 Chen DS. From hepatitis to hepatoma: Lessons from type B viral hepatitis. Science. 1993; 262(5132):369-70.

5 Senger DR, Wirth DF, Hynes RO. Transformed mammalian cells secrete specific proteins and phosphoproteins. Cell. 1979;16(4): 885-93.

6 Young MF, Kerr JM, Termine JD, Wewer UM, Wang MG, McBride OW, et al. cDNA cloning, mRNA distribution and heterogeneity, chromosomal location, and RFLP analysis of human osteopontin (OPN). Genomics. 1990;7(4):491-502.

7 Fet V, Dickinson ME, Hogan BL. Localization of the mouse gene for secreted phosphoprotein 1 (Spp-1) (2ar, osteopontin, bone sialoprotein $1,44-\mathrm{kDa}$ bone phosphoprotein, tumor-secreted phosphoprotein) to chromosome 5, closely linked to Ric (Rickettsia resistance). Genomics. 1989;5(2):375-7.

8 Lund SA, Giachelli CM, Scatena M. The role of osteopontin in inflammatory processes. J Cell Commun Signal. 2009;3(3-4):311-22.

9 Icer MA, Gezmen-Karadag M. The multiple functions and mechanisms of osteopontin. Clin Biochem. 2018;59:17-24.
10 Kawashima R, Mochida S, Matsui A, YouLuTuZ Y, Ishikawa K, Toshima K, et al. Expression of osteopontin in Kupffer cells and hepatic macrophages and stellate cells in rat liver after carbon tetrachloride intoxication: a possible factor for macrophage migration into hepatic necrotic areas. Biochem Biophys Res Commun. 1999;256(3):527-31.

11 Wen Y, Jeong S, Xia Q, Kong X. Role of osteopontin in liver diseases. Int J Biol Sci. 2016; 12(9):1121-8.

12 Liu L, Lu J, Ye C, Lin L, Zheng S, Zhang H, et al. Serum osteopontin is a predictor of prognosis for HBV-associated acute-on-chronic liver failure. Biomed Rep. 2018;8(2):166-71.

13 Abdel-Hafiz SM, Hamdy HE, Khorshed FM, Aboushousha TS, Safwat G, Saber MA, et al. Evaluation of osteopontin as a biomarker in hepatocellular carcinomas in Egyptian patients with chronic HCV cirrhosis. Asian Pac J Cancer Prev. 2018;19:1021-7.

14 Simao A, Madaleno J, Silva N, Rodrigues F, Caseiro P, Costa JN, et al. Plasma osteopontin is a biomarker for the severity of alcoholic liver cirrhosis, not for hepatocellular carcinoma screening. BMC Gastroenterol. 2015; 15:73.

15 Khalil A, Elgedawy J, Faramawi MF, Elfert A, Salama I, Abbass A, et al. Plasma osteopontin level as a diagnostic marker of hepatocellular carcinoma in patients with radiological evidence of focal hepatic lesions. Tumori. 2013; 99(1):100-7.

16 Giraud E, Rouault E, Fiette L, Colle J-H, Smirlis D, Melanitou E. Osteopontin in the host response to Leishmania amazonensis. BMC Microbiol. 2019;19(1):32.
17 Giraud E, Rouault E, Fiette L, Colle JH, Smirlis D, Melanitou E. Osteopontin is upregulated in human and murine acute schistosomiasis mansoni. PLoS Negl Trop Dis. 2016: $10 \mathrm{e} 0005057$.

18 Nau GJ, Guilfoile P, Chupp GL, Berman JS, Kim SJ, Kornfeld H, et al. A chemoattractant cytokine associated with granulomas in tuberculosis and silicosis. Proc Natl Acad Sci USA. 1997;94(12):6414-9.

19 Pascapurnama DN, Labayo HK, Dapat I, Nagarajegowda DD, Zhao J, Zhang J, et al. Induction of osteopontin by dengue virus- 3 infection in thp-1 cells: inhibition of the synthesis by brefelamide and its derivative. Front Microbiol. 2017;8:521.

20 Bassyouni IH, Bassyouni RH, Ibrahim NH, Soliman AF. Elevated serum osteopontin levels in chronic hepatitis $C$ virus infection: association with autoimmune rheumatologic manifestations. J Clin Immunol. 2012;32(6): 1262-9.

21 Fang ZL, Sabin CA, Dong BQ, Ge LY, Wei SC Chen QY, et al. HBV A1762T, G1764A mutations are a valuable biomarker for identifying a subset of male HBsAg carriers at extremely high risk of hepatocellular carcinoma: a prospective study. Am J Gastroenterol. 2008; 103(9):2254-62.

22 Chinese Society of Hepatology, Chinese Medical Association, Chinese Society of Infectious Diseases, Chinese Medical Association. Guideline on prevention and treatment of chronic hepatitis B in China. Chin Med J. 2007;120:2159-73. 
23 Zhao L, Li T, Wang Y, Pan Y, Ning H, Hui X, et al. Elevated plasma osteopontin level is predictive of cirrhosis in patients with hepatitis B Infection. Int J Clin Pract. 2008;62(7):1056-62.

24 Shang S, Plymoth A, Ge S, Feng Z, Rosen HR, Sangrajrang $\mathrm{S}$, et al. Identification of osteopontin as a novel marker for early hepatocellular carcinoma. Hepatology. 2012;55(2): 483-90.

25 Li J, Chen X, Dai M, Huang S, Chen J, Dai S. Diagnostic accuracy of osteopontin plus alpha-fetoprotein in the hepatocellular carcinoma: a meta-analysis. Clin Res Hepatol Gastroenterol. 2017;41(5):543-53.

26 Diao H, Liu X, Wu Z, Kang L, Cui G, Morimoto J, et al. Osteopontin regulates interleukin-17 production in hepatitis. Cytokine. 2012;60(1):129-37.

27 Lamort AS, Giopanou I, Psallidas I, Stathopoulos GT. Osteopontin as a Link between Inflammation and Cancer: the thorax in the spotlight. Cells. 2019;8(8):815.
28 Rittling SR, Singh R. Osteopontin in immunemediated diseases. J Dent Res. 2015;94(12): 1638-45.

29 Cui G, Chen J, He J, Lu C, Wei Y, Wang L, et al. Osteopontin promotes dendritic cell maturation and function in response to HBV antigens. Drug Des Devel Ther. 2015;9:3003-16.

30 Iqbal J, Sarkar-Dutta M, McRae S, Ramachandran A, Kumar B, Waris G. Osteopontin regulates hepatitis $\mathrm{C}$ virus (HCV) replication and assembly by interacting with HCV proteins and lipid droplets and by binding to receptors $\alpha$ V $\beta 3$ and CD44. J Virol. 2018;92:e2116-17.

31 Liu C, Wu W, Shang S, Huang E, Xun Z, Lin J, et al. Application strategies of serum HBV DNA detection in HBV infection patients: a retrospective study of 5611 specimens. J Med Virol. 2019;91:249-57.
32 Buckwold VE, Xu Z, Chen M, Yen TS, Ou JH. Effects of a naturally occurring mutation in the hepatitis B virus basal core promoter on precore gene expression and viral replication. J Virol. 1996;70(9):5845-51.

33 Tang LSY, Covert E, Wilson E, Kottilil S. Chronic hepatitis B infection: a review. JAMA. 2018;319:1802-13.

34 Bartkute K, Balsyte D, Wisser J, Kurmanavicius J. Pregnancy outcomes regarding maternal serum AFP value in second trimester screening. J Perinat Med. 2017;45(7):817-20.

35 Peterson ML, Ma C, Spear BT. Zhx2 and Zbtb20: novel regulators of postnatal alphafetoprotein repression and their potential role in gene reactivation during liver cancer, semin. Cancer Biol. 2011;21:21-7.

36 Daniele B, Bencivenga A, Megna AS, Tinessa V. Alpha-fetoprotein and ultrasonography screening for hepatocellular carcinoma. Gastroenterology. 2004;127(5 Suppl 1):S108-12. 